\title{
PRODUÇÃO DE BIOMASSA DE CANA-DE-AÇÚCAR NO VALE DO SÃO FRANCISCO
}

\author{
Anderson Ramos de Oliveira, Marcos Brandão Braga \& Bruno Leonardo Santana Santos
}

RESUMO: A quantificação da produção de biomassa da parte aérea e radicular é relevante quando se analisa a produção de biocombustível e energia. O presente trabalho teve como objetivo analisar a produção de biomassa no cultivo irrigado da cana soca, sob condições de estresse hídrico. Adotou-se o delineamento em blocos casualizados, tipo fatorial 2 x 4, sendo o primeiro fator constituído por cultivares de cana-de-açúcar: RB 72-454 e RB 92-579 e o segundo fator composto por lâminas de reposição de 40, 60, 80 e 100\% da evapotranspiração da cultura (ETc), em três repetições. Realizaram-se análises biométricas de desenvolvimento e de produção de biomassa da parte aérea e radicular. As cultivares RB 72-454 e RB 92-579 apresentaram número de perfilhos, diâmetro do colmo e altura semelhantes. A altura do colmo foi menor quando se utilizou lâmina de reposição de apenas $40 \%$ da ETc. A produção média de palha de $32,42 \mathrm{t} \mathrm{ha}^{-1}$ e colmos de $130,73 \mathrm{t} \mathrm{ha}^{-1}$ das cultivares foi maior do que a média nacional. A elevada produção de palha no cultivo da cana-de-açúcar irrigada no semiárido apresenta potencial para cogeração de energia e a elevada produção de biomassa total pode agregar valor à atividade, por meio da obtenção de créditos de carbono.

PALAVRAS-CHAVE: Palhada, energia, cana soca, semiárido, estresse hídrico.

\section{BIOMASS PRODUCTION OF IRRIGATED SUGARCANE IN SAO FRANCISCO VALLEY BRAZIL}

\begin{abstract}
The quantification of biomass production is relevant when considering the production of biofuel and energy. This study aimed to analyze the biomass production in irrigated sugarcane ratoon under water stress conditions. It was adopted a randomized block design, type $2 \times 4$ factorial, the first factor consists of cultivars sugarcane: RB 72-454 and RB 92-579 and the second, applications of irrigation water using 40, 60, 80 and 100\% of crop evapotranspiration (ETc), in three replications. Biometric development and biomass production of root and shoot analyses were performed. The cultivars RB 72-454 and RB 92-579 showed similar tiller, stem diameter, and height .The stem height was lower when only $40 \%$ of ETc was replaced to the soil. The cultivars average yield of straw $\left(32.42 \mathrm{tha}^{-1}\right)$ and stems $\left(130.73 \mathrm{tha}^{-1}\right) \mathrm{were}^{\mathrm{s}}$ higher than the national average. The straw high production in the irrigated cultivation of sugarcane at the semiarid shows an energy cogeneration potential and the high total biomass production can add value to the sugarcane activity, by obtaining carbon credits.
\end{abstract}

KEYWORDS: Straw, energy, cane ratoon, semiarid, water stress.

\footnotetext{
1 Embrapa Semiárido. Pesquisador da Embrapa Semiárido. E-mail: anderson.oliveira@embrapa.br

${ }^{2}$ Embrapa Hortaliças. Pesquisador da Embrapa Hortaliças. E-mail:

marcos.braga@embrapa.br

${ }^{3}$ Universidade de Pernambuco. Departamento de Ciências Biológicas.

E-mail: bruno_leo_@hotmail.com
} 


\section{INTRODUÇÃO}

A oferta total de petróleo no mundo tem se mantido relativamente constante, em um patamar aproximado de 80 milhões de barris/dia. Contudo, estima-se que as cotações médias do preço do barril do petróleo no mercado internacional devam aumentar em 43,1\% até 2020 (ERNEST \& YOUNG TERCO, 2011). Sabe-se que a utilização de fontes energéticas fósseis (petróleo) é finita, altamente poluente e de custo elevado (GOLDEMBERG, 2000; HILGEMBERG; GUILHOTO, 2006; VICHI; MANSOR, 2009). Aliada às altas constantes nos preços dos derivados do petróleo e à necessidade cada vez maior de buscar alternativas sustentáveis para atender à demanda por combustíveis e, principalmente, por energia, o setor sucroalcooleiro brasileiro tornou-se mais competitivo nos últimos anos.

O cultivo da cana-de-açúcar apresenta-se com grande potencial para suplementação de energia, tanto no que diz respeito à produção de etanol, quanto à produção de energia elétrica por meio da queima do bagaço nas usinas. Os complexos de processamento nas usinas estão estruturados para receberem os colmos da cana-deaçúcar provenientes da colheita e retirarem o caldo para a produção do etanol. O resíduo que sobra da prensagem da cana, o bagaço, é prontamente utilizado pela usina nas caldeiras, produzindo energia elétrica, que a torna autossuficiente em relação à energia elétrica para as mais variadas atividades. Além disso, há usinas que comercializam o excedente de produção para concessionárias de energia elétrica. Segundo a CONAB (2011), toda energia utilizada no processo industrial da produção de etanol e açúcar no Brasil é gerada dentro das próprias usinas a partir da queima do bagaço da cana. Essa energia é produzida para suprir a necessidade da usina, mas acredita-se que com uma política de incentivo essas usinas possam contribuir, ainda mais com o mercado de produção de energia, fornecendo a energia proveniente da biomassa para a rede pública de energia elétrica. De acordo com Ripoli et al. (2005), o potencial de utilização de resíduos de cana-de-açúcar para o uso na cogeração de energia elétrica no Brasil pode resultar em 41,46 x $10^{6} \mathrm{MWh}$ por safra, considerando uma máxima utilização dos resíduos.

Ainda que a pressão da sociedade tenha tido efeitos significativos na mudança de leis e na obrigatoriedade da redução da queima dos canaviais no processo de colheita, verifica-se que em grande parte das áreas produtoras de cana-de-açúcar do país a prática da queimada é utilizada em larga escala. Tal prática, apesar de facilitar o trabalho dos cortadores, traz prejuízos enormes ao meio ambiente, pois reduz a biodiversidade do solo, por eliminar os microorganismos e a macrofauna presente nas áreas de produção (REDIN et al., 2011), reduz a produção de matéria orgânica (CANELLAS et al., 2007; CZYCZA, 2009), componente fundamental na qualidade do solo, por permitir maior oscilação da temperatura na superfície do solo e diminui a manutenção da umidade, notadamente em regiões de clima mais quente (RONQUIM, 2010). Além destes fatores, a queima prejudica a saúde das pessoas que residem em locais próximos à usina, causando problemas respiratórios (RIBEIRO, 2008). Acrescente-se a estes fatores a emissão de gases de efeito estufa (GEE), principalmente o dióxido de carbono $\left(\mathrm{CO}_{2}\right)$.

Assim, a colheita da cana crua reveste-se da maior importância, por permitir maior sustentabilidade à atividade canavieira. Contudo, a permanência de toda a palhada no solo prejudica o desenvolvimento da cultura, pois a germinação das gemas e o desenvolvimento dos perfilhos podem ser comprometidos. Orlando Filho et al. (1994) citam como desvantagem o possível retardamento da brotação e a redução em até $52 \%$ da produtividade agrícola na variedade SP 71-6163. De acordo com Campos et al. (2010), a manutenção da palha de cana-deaçúcar em área total sobre o solo, após colheita sem queima, prejudica o desenvolvimento da soqueira, que apresenta menor produtividade e biomassa de perfilhos. Este fato ganha importância particular quando se considera que as variedades de cana-de-açúcar disponíveis atualmente foram desenvolvidas em sistema de cana queimada, de modo que cada variedade pode apresentar resposta diferente quanto à adaptabilidade a mudanças, não apenas em aspectos físicos, mas também quanto às particularidades do manejo. Por outro lado, Alvarez e Castro (1999) estudando o crescimento da parte área de cana crua e cana queimada, concluíram que o perfilhamento da cana crua não apresenta diferenças significativas que confirmem a influência negativa da palha na rebrota.

O bagaço da cana-de-açúcar e os demais resíduos (ponteiros, folhas verdes e palhas) podem ser recolhidos e queimados para produção de vapor para geração de eletricidade ou convertidos em álcool carburante, diminuindo a grande poluição atmosférica causada pela queima de canaviais e tem grande potencial para ser usado para melhorar e diversificar a matriz energética do Brasil (RIPOLI et al., 2000). De acordo com Chandel et al. (2011), os subprodutos gerados durante o processamento agro-industrial da cana-de-açúcar, bagaço e palhada, constituem fontes potenciais de carboidratos que podem ser utilizados para gerar produtos de valor de alto interesse comercial. Atualmente, o bagaço é queimado em caldeiras como uma fonte mais barata de energia e a integração de operações do processo, como a hidrólise, a desintoxicação, a fermentação, a destilação seria uma estratégia eficaz para maximizar a utilização de todos os demais subprodutos da colheita da cana.

Segundo Lamonica (2006), o setor possui ainda grande potencial de geração de excedentes de energia elétrica utilizando apenas o bagaço e/ou a palha como combustível, em ciclos convencionais, podendo chegar a 194.400 TJ/ano (54 TWh/ano) com preços inferiores aos obtidos pela geração com biogás.

Em estudo realizado por Beeharry (2001), com o intuito de avaliar a produção de energia e resíduos a partir da biomassa da cana-de-açúcar, foi observado que a produção de energia pode ser aumentada em $50 \%$ usando o bagaço, as folhas e a palha da cana, em uma cadeia de produção de energia. Florentino et al. (2008) relatam que 
as diferentes cultivares podem gerar custos diferentes no processo de transferência da biomassa residual da colheita para a usina e demonstraram a viabilidade do uso de modelos matemáticos para otimizar o lucro do uso da biomassa residual de colheita para geração de energia, levando-se em consideração a cultivar utilizada, a distância entre os talhões e o centro de processamento.

Nas regiões produtoras de cana-de-açúcar contabiliza-se que a produção de palhada gire em torno de 12 a 20 toneladas por hectare (ABRAMO FILHO et al., 1993). Porém, considerando-se a produção em sistemas de cultivos irrigados por gotejamento subsuperficial, espera-se que ocorra maior produção de palhada, uma vez que a produção de colmos também é maior.

Na região semiárida do Nordeste brasileiro, notadamente no Vale do São Francisco, a utilização de sistemas irrigados permitiu o desenvolvimento da atividade canavieira. O cultivo tem como grande diferencial a disponibilidade de água durante todo o período produtivo. Este fornecimento de água permite maior produtividade, principalmente pelo fato de que nas fases de maior desenvolvimento da cultura não há restrição hídrica. Dentre os manejos de irrigação adotados na região, o uso de sistemas de maior precisão tem sido mais recomendado, uma vez que se busca a maior eficiência no uso da água, ou seja, busca-se a maior produtividade utilizando-se menores lâminas de irrigação. Isso porque, menores lâminas de irrigação representam menor custo de água, menor custo de captação da água e menor custo de distribuição, aliado ao apelo de sustentabilidade. Não se pode mais negligenciar o atendimento das necessidades presentes e nem utilizar-se dos recursos naturais disponíveis sem comprometimento com as gerações futuras.

No centro-sul, por ter períodos de chuvas bem definidos e alto índice pluviométrico, a prática da irrigação não é muito utilizada (SOUZA, 2005). Entretanto, algumas usinas utilizam-se de irrigação para aumentar a produção.

$\mathrm{Na}$ cultura da cana-de-açúcar é possível adotar a irrigação por gotejamento e gotejamento subsuperficial. Este último destaca-se pelo avançado caráter tecnológico e pela maior eficiência no uso da água, uma vez que a água é fornecida próxima à raiz da cultura, por facilitar a mecanização da área cultivada, entre outros (AMORIM et al., 2007). Apesar do alto investimento, o sistema de gotejamento proporciona maior produtividade. Segundo Vieira (2012), a produtividade média de áreas irrigadas por gotejamento na Usina Agrovale, Juazeiro - BA, no ano de 2011 foi de $115 \mathrm{tha}^{-1}$.

A busca por alternativas bioenergéticas e o comprometimento de vários países, notadamente, dos países europeus na redução das emissões dos GEE, criou o Mecanismo de Desenvolvimento Limpo (MDL) que possibilita que os países em desenvolvimento, como é o caso do Brasil, ao reduzirem a emissão de $\mathrm{CO}_{2}$ em uma tonelada ganhem crédito de carbono (GODOY; PAMPLONA, 2007). Esses créditos podem ser comercializados com os países desenvolvidos. Desta forma, o Brasil por ser o maior produtor de cana-deaçúcar, desponta-se com grande potencial na redução de emissão de GGE e no sequestro de $\mathrm{CO}_{2}$. Contudo, para que sejam validados estes créditos de carbono, fazem-se necessários estudos de quantificação da produção de biomassa da cana-de-açúcar, uma vez que, a maioria dos estudos apresenta apenas a produtividade da cana-deaçúcar e não considera a produção de palhada e nem a produção de biomassa do sistema radicular. Notam-se dois pontos relevantes: o primeiro é a quantificação da produção de biomassa da parte aérea da cana-de-açúcar, incluindo a palhada para fins de produção de energia elétrica e o segundo, é a quantificação da produção de biomassa do sistema radicular, somada à produção de biomassa da parte aérea, para fins de mensuração do sequestro de carbono e, posterior, comercialização de créditos de carbono.

Dentro deste contexto, fazem-se necessários estudos de quantificação da produção de biomassa da cana-deaçúcar quando submetida ao estresse hídrico. Assim, o presente trabalho tem como objetivo quantificar a produção de biomassa da parte aérea e do sistema radicular de duas cultivares de cana-de-açúcar irrigadas por gotejamento subsuperficial e submetidas ao estresse hídrico, buscando-se determinar tal produção para fins de cogeração de energia e para fins futuros de comercialização de créditos de carbono.

\section{MATERIAL E MÉTODOS}

O trabalho foi desenvolvido no Campo Experimental de Bebedouro, pertencente à Embrapa Semiárido, em Petrolina - PE, com latitude $09^{\circ} 09^{\prime} \mathrm{S}$, longitude $42^{\circ} 22^{\prime}$ $\mathrm{W}$ e altitude de $365,5 \mathrm{~m}$. O clima da região, segundo a classificação de Köppen, é tropical semiárido tipo BshW, seco e quente. O solo é do tipo Argissolo Vermelho-Amarelo eutrófico, cujas características químicas são: $\mathrm{MO}$ de $13,14 \mathrm{~g} / \mathrm{kg} ; \mathrm{pH}\left(\mathrm{H}_{2} \mathrm{O}\right) 6,4 ; 0,21$ $\mathrm{d} / \mathrm{Sm} ; 32,28 \mathrm{mg} / \mathrm{dm}^{3}$ de $\mathrm{P} ; 0,38 \mathrm{cmol}_{\mathrm{c}} / \mathrm{dm}^{3}$ de $\mathrm{K} ; 1,5$ $\mathrm{cmol}_{\mathrm{c}} / \mathrm{dm}^{3}$ de $\mathrm{Ca} ; 1,2 \mathrm{cmol}_{\mathrm{c}} / \mathrm{dm}^{3}$ de $\mathrm{Mg} ; 0,03 \mathrm{cmol}_{\mathrm{c}} / \mathrm{dm}^{3}$ de $\mathrm{Na} ; 0,05 \mathrm{cmol}_{\mathrm{c}} / \mathrm{dm}^{3}$ de $\mathrm{Al} ; 2,31 \mathrm{cmol}_{\mathrm{c}} / \mathrm{dm}^{3}$ de $\mathrm{H}+\mathrm{Al}$; $3,11 \mathrm{cmol}_{\mathrm{c}} / \mathrm{dm}^{3}$ de $\mathrm{S}$ (bases); 5,42 $\mathrm{cmol}_{\mathrm{c}} / \mathrm{dm}^{3}$ de CTC e $57 \%$ de saturação de bases, conforme análise realizada no Laboratório de Solos da Embrapa Semiárido.

Adotou-se o delineamento em blocos casualizados, tipo fatorial $2 \times 4$, sendo o primeiro fator constituído por duas cultivares de cana-de-açúcar: RB 72-454 e RB 92-579 e o segundo fator composto por quatro lâminas de reposição da evapotranspiração da cultura (ETc): 40, 60, 80 e $100 \%$ da ETc, em três repetições. A diferenciação das lâminas ocorreu após as fases 1 (germinação e emergência) e 2 (perfilhamento e estabelecimento da cultura) de desenvolvimento da cultura, que correspondeu a 150 dias após a primeira colheita.

Segundo a Rede Interuniversitaria para o Desenvolvimento do Setor Sucroalcooleiro - RIDESA (2010), a cultivar RB 92-579 apresenta, no primeiro e segundo ano de cortes, bom perfilhamento, com velocidade regular de crescimento e alta produtividade 
agrícola, sendo uma cultivar com resistência média à seca. A cultivar RB 72-454, por sua vez, apresenta-se como cultivar padrão em diversos estudos por apresentar perfilhamento médio, com raro tombamento e alta produtividade agrícola.
O monitoramento das condições meteorológicas foi realizado em estação convencional, instalada em área plana com grama. As médias das variáveis de evaporação (obtida em tanque Classe A), precipitação, temperatura média e umidade relativa são apresentadas na Figura 01.

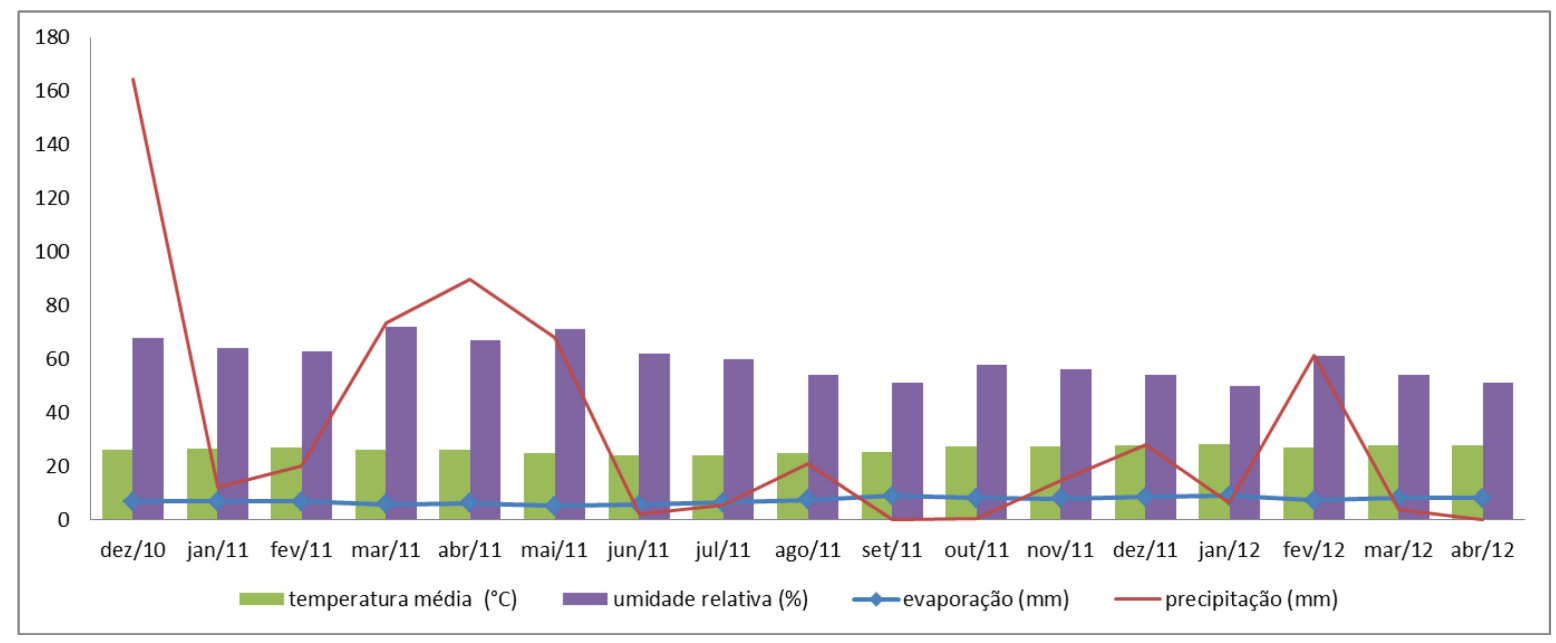

Figura 01 - Condições meteorologicas observadas durante o período de condução do experimento. Estação Meteorológica Convencional de Bebedouro. Embrapa Semiárido, Petrolina - PE, 2010-2011.

Cada parcela foi constituída por duas linhas duplas de plantio com $15 \mathrm{~m}$ de comprimento, sendo que apenas os cinco metros centrais foram considerados como área útil e os cinco metros iniciais e finais foram considerados bordadura.

Utilizou-se o sistema de irrigação por gotejamento subsuperficial com emissores autocompensantes espaçados em $0,3 \mathrm{~m}$ entre si e divididos em quatro lâminas diferentes. $\mathrm{O}$ monitoramento da umidade do solo, para dar subsídios aos cálculos de irrigação, foi realizado três vezes por semana, utilizando-se de tensiômetros, nas profundidades de 0,$10 ; 0,30$ e $0,50 \mathrm{~m}$ e, também, semanalmente, utilizando-se a sonda de nêutrons, em profundidades de 0,$20 ; 0,40 ; 0,60 ; 0,80$ e $1,0 \mathrm{~m}$, com intuito de auxiliar no monitoramento da umidade, pois em condições de maior restrição hídrica, os tensiômetros apresentam limitação de uso. Curvas de retenção de água no solo, realizadas com amostras indeformadas, auxiliaram no monitoramento da umidade do solo nos diferentes tratamentos.

A adubação foi realizada de acordo com a análise de solo, considerando-se produtividade superior a $100 \mathrm{t} \mathrm{ha}^{-1}$. A distribuição do nitrogênio e potássio foi feita via fertirrigação seguindo-se a curva de absorção de nutrientes obtida por Bachchhav (2005).

O trabalho foi desenvolvido em cana soca, tendo seu início em dezembro de 2010 e estendendo-se até novembro de 2011, mês em que se realizou a colheita.

\section{Análise Biométrica}

Durante o experimento avaliou-se o perfilhamento e realizaram-se avaliações biométricas de altura e diâmetro do colmo. O número de perfilhos foi obtido por meio da divisão do número total de perfilhos computados na área útil de cada parcela e expressos em número de perfilhos por metro linear. A análise do perfilhamento foi realizada nos meses maio e julho.

A biometria da altura das plantas e do diâmetro médio do colmo foi realizada nos meses de maio, julho, outubro e novembro de 2011. Escolheram-se três plantas, de forma aleatória dentro da área útil de cada linha de plantio, na primeira avaliação, as quais foram identificadas por meio de uma fita, a fim de que todas as avaliações seguintes fossem realizadas com as mesmas plantas. Para registrar o diâmetro do colmo, utilizou-se paquímetro digital e retirou-se a média de três observações realizadas entre o quinto e o sexto entrenó das três plantas selecionadas, sendo que cada uma constituiu-se em uma repetição. Para avaliação da altura da planta, utilizou-se uma trena graduada e fez-se a medida da distância do solo até a lígula da primeira folha aberta.

Os dados foram submetidos à análise de variância a fim de se verificar se houve interação entre os fatores (cultivares e lâminas de reposição da ETc) ou se os fatores atuaram separadamente. Em caso positivo, as médias foram comparadas pelo teste de Duncan a 5\% de probabilidade. 


\section{Análise da Fitomassa}

A fim de estimar a produção de fitomassa aérea, toda a área útil foi pesada por ocasião da colheita. $\mathrm{O}$ corte foi realizado manualmente com auxilio de facões, e pesaram-se todos os colmos presentes na área útil com auxilio de trator e balança analógica.

Realizaram-se ainda a coleta de amostras de palha e colmo de forma aleatória dentro da área útil de cada parcela experimental. As amostras consistiram de seis a nove colmos, sem palha e ponteira, que foram submetidos imediatamente à pesagem para obtenção do peso fresco. Em seguida as amostras foram devidamente identificadas e levadas ao laboratório de solos da Embrapa Semiárido onde ficaram por 72 horas na estufa a $75^{\circ} \mathrm{C}$. Após esse período, os colmos foram pesados a fim de se obter o peso da biomassa seca.

Coletou-se, ainda, toda a palhada (palha e ponteira) dos colmos de um metro linear na área útil de cada parcela. Tal como no procedimento adotado para os colmos, a palha foi pesada para obtenção da biomassa fresca e, logo após, foi encaminhada para o Laboratório de Solos, seguindo o procedimento de secagem em estufa e posterior pesagem do material seco para aferição da biomassa seca da palha.

Os dados obtidos foram submetidos à análise de variância e posterior comparação de médias por meio do teste de Duncan a 5\%.

$\mathrm{Na}$ avaliação da produção de biomassa do sistema radicular realizou-se, imediatamente após a colheita, a abertura de duas trincheiras na cultivar RB 72-454 e duas trincheiras na cultivar RB 92-579 nas parcelas submetidas à lâmina de reposição da ETc de 100\%. Nas quatro trincheiras coletaram-se as raízes das cultivares, desconsiderando-se o tolete que originou a touceira. As trincheiras foram dimensionadas para que fosse retirado $1,0 \mathrm{~m}^{3}$ de solo + raízes. Em cada trincheira foram retiradas cinco repetições de $0,20 \mathrm{~m} \times \quad 0,20 \mathrm{~m}$ (comprimento e largura) em cinco profundidades: 00,$10 ; 0,10-0,20 ; 0,20-0,40 ; 0,40-0,60$ e $0,60-1,00 \mathrm{~m}$.

Nas diferentes camadas foram retirados monólitos de solo com auxílio de duas espátulas e levados para peneira de $0,05 \mathrm{~mm}$ onde se realizou o processo de separação das raízes do solo com auxílio de um jato de água, baseado em metodologia de Otto et al. (2009). Obtidas as raízes, as mesmas foram transferidas para sacos de papel e pesadas em balança digital de precisão para obtenção da biomassa fresca. Logo após foram conduzidas ao Laboratório de Solos da Embrapa Semiárido para secagem em estufa de ventilação forçada à temperatura de $75^{\circ} \mathrm{C}$ por 72 horas. Decorrido o período de secagem as amostras foram novamente submetidas à pesagem para obtenção da biomassa seca das raízes.

\section{RESULTADOS E DISCUSSÃO} Análise Biométrica das Cultivares em Função das
Lâminas de Irrigação
Nas avaliações de número de perfilhos não houve interação entre os fatores cultivares de cana-de-açúcar e lâminas de irrigação. A análise de variância demonstrou, ainda, que não houve diferenças entre cultivares e nem entre as lâminas de irrigação, quando as mesmas foram estudadas separadamente (Tabela 1).

Tabela 1 - Quadrados médios para número de perfilhos da cana-de-açúcar aos 150 e 210 dias após a primeira colheita.

\begin{tabular}{lccc}
\hline \multicolumn{1}{c}{ F. V. } & GL & $\mathbf{1 5 0}$ & $\mathbf{2 1 0}$ \\
\hline $\mathrm{C}$ & 1 & $240.6667^{\mathrm{ns}}$ & $2.6667^{\mathrm{ns}}$ \\
$\mathrm{L}$ & 3 & $47.6667^{\mathrm{ns}}$ & $205.5555^{\mathrm{ns}}$ \\
$\mathrm{C} * \mathrm{~L}$ & 3 & $59.0^{\mathrm{ns}}$ & $153.3333^{\text {ns }}$ \\
\hline $\mathrm{B}$ & 2 & 72.5416 & 360.7916 \\
\hline $\mathrm{R}$ & 14 & 162.1131 & 415.3155 \\
\hline
\end{tabular}

Onde: F.V. - fonte de variação; $\mathrm{C}=$ cultivares; $\mathrm{L}=$ lâminas de reposição hídrica; $\mathrm{B}=$ blocos; $\mathrm{R}=$ resíduo; $\mathrm{GL}=$ grau de liberdade; ${ }^{\text {ns }}=$ não significativo $\mathrm{e}^{*}$ significativo pelo teste $\mathrm{F}$ a $5 \%$ de probabilidade.

Essa não diferenciação entre os tratamentos é explicada pelo fato de que as lâminas de irrigação não foram diferenciadas até 150 dias após a colheita (DAC), ou seja, as cultivares foram submetidas à mesma lâmina de irrigação que correspondia a $100 \%$ da ETc. Assim, as cultivares se comportaram da mesma forma, uma vez que o perfilhamento acontece principalmente nos primeiros meses após a colheita. Estes resultados corroboram com o trabalho de Casagrande (1991), que observou que o perfilhamento da cana-de-açúcar geralmente atinge seu máximo no quarto mês após o plantio. De acordo com Bernardo (2006), é de fundamental importância definir os estágios de desenvolvimento da cultura a fim de otimizar a eficiência de aplicação da irrigação.

Nota-se, na Tabela 02, que mesmo não havendo diferenças entre as cultivares e entre as lâminas de irrigação, o numero de perfilhos por metro linear aumentou de uma avaliação para outra. Sendo que o número médio de perfilhos por metro linear foi de 14,34 e 16,63 aos 150 e 210 DAC, respectivamente. Barbosa et al. (2012) ao estudarem a cultivar RB 85-5536 observaram que o tratamento irrigado via gotejamento subsuperficial e aplicação dos nutrientes NPK, via fertirrigação, proporcionou 17,3 perfilhos por metro linear aos 330 dias. Oliveira et al. (2004) relatam que a cultivar RB 72-454 tem perfilhamento constante e que atinge o máximo de perfilho por volta dos 231 DAP (dias após o plantio), sob regime de precipitação normal para a região. Almeida et al. (2008) ao estudarem os padrões de crescimento e de produção de variedades de cana-de-açúcar com os graus-dias e disponibilidade hídrica, com irrigação na fase de estabelecimento da cultura, durante os cultivos de cana-planta e cana-soca defenderam que o pico de perfilhamento da cultivar RB 92-579 na cana-soca é atingido aos 60 DAC. Costa (2009) ao avaliar o crescimento, os pigmentos fotossintéticos foliares e a produtividade de quatro 
variedades de cana-de-açúcar, observou que o número máximo de perfilhos da cultivar RB 92-579 na cana-soca se encontra aos 90 DAC.

Tabela 02 - Número de perfilhos (média) das cultivares de cana-de-açúcar $R B$ 72-454 e RB 92-579 irrigadas por gotejamento subsuperficial.

\begin{tabular}{ccc}
\hline $\begin{array}{c}\text { Dias Após o Corte } \\
\text { (DAC) }\end{array}$ & $\mathbf{1 5 0}$ & $\mathbf{2 1 0}$ \\
\hline & \multicolumn{2}{c}{$\begin{array}{c}\text { Número de Perfilhos } \\
\text { (m linear) }\end{array}$} \\
\hline Média & 14,34 & 16,63 \\
\hline Teste F & $0,3694^{\text {n.s. }}$ & $0,3692^{\text {n.s. }}$ \\
C.V. & 17,77 & 24,50 \\
\hline
\end{tabular}

Onde: ${ }^{\text {n.s. }}$ não significativo pelo teste $\mathrm{F}$ a $5 \%$ de probabilidade.

De acordo com a análise de variância para diâmetro e altura, a interação entre os fatores cultivares de cana-deaçúcar e lâminas de irrigação e a análise isolada das cultivares foi não significativa pelo teste F. No entanto, houve significância para a análise do diâmetro e da altura em função das lâminas de irrigação, conforme pode ser observada na Tabela 03 .

Tabela 03 - Médias de diâmetro $(\mathrm{mm})$ e altura $(\mathrm{m})$ das cultivares de cana-de-açúcar $R B$ 72-454 e RB 92-579 em função das diferentes lâminas de irrigação.

\begin{tabular}{cccccccccc}
\hline & \multicolumn{3}{c}{ Diâmetro (mm) } \\
\cline { 2 - 9 } \begin{tabular}{c} 
ETc \\
\cline { 2 - 8 }
\end{tabular} & \multicolumn{9}{c}{ Dias Após o Corte (DAC) } \\
\cline { 2 - 9 } & $\mathbf{1 5 0}$ & $\mathbf{2 1 0}$ & $\mathbf{3 0 0}$ & $\mathbf{3 3 0}$ & $\mathbf{1 5 0}$ & $\mathbf{2 1 0}$ & $\mathbf{3 0 0}$ & $\mathbf{3 3 0}$ \\
\hline 40 & 28,19 & $26,70 \mathrm{~b}$ & 27,78 & 24,05 & 1,65 & 2,88 & 3,15 & $3,52 \mathrm{~b}$ \\
60 & 28,06 & $28,58 \mathrm{a}$ & 28,55 & 29,00 & 1,70 & 3,13 & 3,50 & $3,89 \mathrm{a}$ \\
80 & 26,30 & $26,37 \mathrm{~b}$ & 28,22 & 25,41 & 1,66 & 2,93 & 3,37 & $3,94 \mathrm{a}$ \\
100 & 25,76 & $25,41 \mathrm{~b}$ & 28,00 & 24,38 & 1,44 & 2,93 & 3,32 & $3,68 \mathrm{a}$ \\
\hline d.m.s. & 3,20 & 4,58 & 3,96 & 5,39 & 0,38 & 0,45 & 0,59 & 0,35 \\
\hline Média & 27,08 & & 28,14 & 25,71 & 1,62 & 2,97 & 3,33 & \\
\hline Onde: & d.m.s. & & diferença & mínima & significativa. & Médias
\end{tabular}

Onde: d.m.s. = diferença mínima significativa. Médias seguidas pela mesma letra na coluna não diferem entre si pelo teste de Duncan a 5\% de probabilidade.

Observou-se que o diâmetro das cultivares submetidas à lâmina de irrigação de $60 \%$ da ETc, aos 210 DAC, apresentou maior valor que as demais lâminas de irrigação. Contudo, nas demais avaliações não houve diferenças entre os diâmetros em função das lâminas de irrigação. Dalri e Cruz (2002) avaliaram o efeito da frequência da irrigação subsuperficial por gotejamento, baseadas na ETc, no desenvolvimento da cana-de-açúcar RB 72-454 e constataram que não houve diferença estatística em diâmetro da cultivar entre os diferentes regimes de frequência de irrigação. Todavia, a irrigação proporcionou aumento na produção de biomassa fresca e seca dos colmos em relação às parcelas não irrigadas. De acordo com Costa (2009), o diâmetro é a variável de crescimento que apresenta menor variação, pois essa variável depende das características genéticas da variedade, do número de perfilhos, do espaçamento utilizado, da área foliar e das condições climáticas e ambientais. Em estudo sobre o crescimento, pigmentos fotossintéticos e produtividade de cana-de-açúcar no quarto ciclo de cultivo, ainda de acordo com Costa (2009), observou-se que a cultivar RB 92-579 apresenta diâmetro médio de $23,3 \mathrm{~mm}$. Outros autores, ao analisarem tal característica observaram valores de diâmetros semelhantes ao encontrado no presente trabalho. Oliveira et al. (2004) encontraram valores de $26 \mathrm{~mm}$ para a variedade RB 72-454 e Santos (2006) observou diâmetro médio de 23,3 mm, enquanto Barbosa (2005) relatou ter encontrado diâmetro médio de 32,2 $\mathrm{mm}$ na cultivar RB 72-454 quando irrigada.

Silva et al. (2008) registraram que o diâmetro de colmos não foi um indicador capaz de refletir diferenças em cana-de-açúcar cultivada sobre diferentes regimes hídricos. Dias et al. (2012) concordam que o diâmetro de colmos não responde à disponibilidade hídrica no solo.

Ao se analisar a variável altura das cultivares em função das lâminas de irrigação observou-se que não houve diferenças entre as alturas nas avaliações aos 150, 210 e 300 DAC. Contudo, aos 330 DAC, as parcelas que receberam reposição hídrica de $40 \quad \% \quad$ da $\quad$ ETc apresentaram canas com altura inferior às demais parcelas (Figura 02).

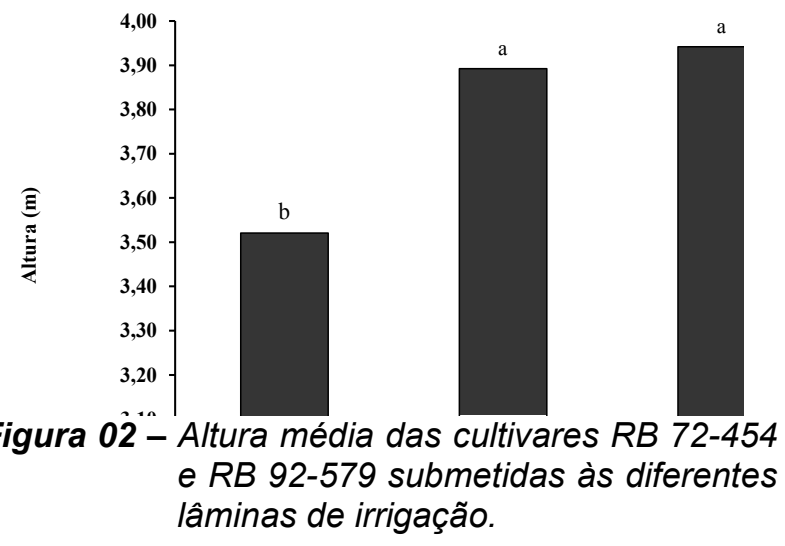

Silva et al. (2012) ao estudarem o desenvolvimento da cultura de cana-de-açúcar em resposta a diferentes lâminas de água via sistema de irrigação por gotejamento subsuperficial, observaram que a altura da cana-deaçúcar submetida a 75 e $100 \%$ de reposição hídrica apresentaram-se estatisticamente iguais e superiores àquelas submetidas à reposição hídrica de 50 e $25 \%$. Trabalhando com a cultivar SP 71-6949, Freitas et al. (2012) observaram altura média de plantas irrigadas por gotejamento subsuperficial de $3,90 \mathrm{~m}$. Oliveira et al. (2012), avaliando o crescimento da cultura da cana-deaçúcar, no primeiro ano, em resposta a diferentes lâminas de reposição hídrica, via sistema de irrigação por gotejamento subsuperficial, concluíram que lâminas que correspondem a 75 e $100 \%$ de reposição hídrica não diferem entre si e maior investimento em altura é 
alcançado. Varela (2002), ao estudar o comportamento morfofisiológico da cana-planta irrigada, relata que o período crítico da cana-de-açúcar quanto ao déficit hídrico, corresponde ao período máximo de crescimento vegetativo, que corresponde aos primeiros oito meses de vida. Considerando que as cultivares permaneceram durante cinco meses submetidas a maior lâmina de irrigação e que, desta forma, durante o período crítico de déficit hídrico as cultivares receberam menores lâminas apenas durante três meses, as diferenças nas alturas foram registradas ao final do ciclo da cultura e mesmo assim, apenas entre a menor lâmina se comparada às lâminas de 60, 80 e 100\%. Corroborando com estas avaliações, Farias et al. (2008) observaram que aos 190 dias, aproximadamente, é estabilizado o crescimento da cana irrigada.

\section{Análise da Produção de Fitomassa da Parte Aérea}

A análise de variância para a maioria das variáveis de produção resultou em não significância para a interação cultivares de cana-de-açúcar e lâminas de irrigação. A análise isolada dos fatores resultou em não significância para biomassa fresca da palha (BFP), biomassa seca da palha (BSP), biomassa fresca do colmo (BFC) e biomassa seca do colmo (BSC). Por outro lado, em relação à biomassa fresca total (BFT) e biomassa seca total (BST) observa-se que, para o fator lâminas de irrigação, o teste $\mathrm{F}$ apresentou significância, ou seja, há diferenças entre lâminas de irrigação quanto à produção de fitomassa (Tabela 04).

Tabela 04 - Quadrados médios para biomassa fresca da palha (BFP), biomassa seca da palha (BSP), biomassa fresca do colmo (BFC, biomassa seca do colmo (BSC), biomassa fresca total (BFT) e biomassa seca total (BST) em função de diferentes cultivares e lâminas de irrigação.

\begin{tabular}{lccccccc}
\hline \multicolumn{1}{c}{ F. V. } & GL & BFP & BSP & BFC & BSC & BFT & BST \\
\hline C & 1 & $268.9381^{\text {ns }}$ & $257.349^{\text {ns }}$ & $1564.127^{\text {ns }}$ & $291.6813^{\text {ns }}$ & $3130.22^{\text {ns }}$ & $1096.9872^{\text {ns }}$ \\
L & 3 & $222.3260^{\text {ns }}$ & $138.7004^{\text {ns }}$ & $1673.3402^{\text {ns }}$ & $886.6556^{\text {ns }}$ & $3045.2811^{*}$ & $1687.9883^{*}$ \\
C $*$ L & 3 & $102.2813^{\text {ns }}$ & $90.2606^{\text {ns }}$ & $591.9053^{\text {ns }}$ & $294.8674^{\text {ns }}$ & $1082.7388^{\text {ns }}$ & $474.4190^{\text {ns }}$ \\
\hline B & 2 & 80.3457 & 136.981 & 71.1946 & 57.6373 & 39.0391 & 16.913 \\
\hline R & 14 & 97.0447 & 94.5755 & 925.446 & 448.599 & 814.8898 & 397.7350 \\
\hline C.V. & --- & 30.374 & 34.564 & 23.270 & 24.346 & 17.495 & 17.322
\end{tabular}

Onde: F.V. - fonte de variação; $\mathrm{C}=$ cultivares; $\mathrm{L}=$ lâminas de reposição hídrica; $\mathrm{B}=$ blocos; $\mathrm{R}=$ resíduo; C.V. = coeficiente de variação; $\mathrm{GL}=$ grau de liberdade; $\mathrm{BFP}=$ biomassa fresca da palha; $\mathrm{BSP}=$ biomassa seca da palha; $\mathrm{BFC}=$ biomassa fresca do colmo; $\mathrm{BSC}=$ biomassa seca do colmo; BFT = biomassa fresca total; BST = biomassa seca total; ${ }^{\text {ns }}$ = não significativo pelo teste $\mathrm{F}$ e " significativo pelo teste $\mathrm{F}$ a $5 \%$ de probabilidade.

A Tabela 05 apresenta o resultado do teste de Duncan (5\%) para as cultivares em função das lâminas de irrigação. Estima-se que para cada tonelada de cana colhida gera-se $280 \mathrm{~kg}$ de palhas (PAOLIELLO, 2006), o que corresponde a, aproximadamente, $23 \mathrm{tha}^{-1} \mathrm{em}$ condições de sequeiro. Para Abramo Filho et al. (1993), a produção de palhada de cana varia entre 10 e $20 \mathrm{t} \mathrm{ha}^{-1}$ /ano. Paes \& Oliveira (2005) relatam que a quantidade média de palha sobre o solo após a colheita mecanizada é 14 $\mathrm{t} \mathrm{ha}^{-1}$. A produtividade média de palha em condições irrigadas, como aconteceu no presente trabalho, é maior: $32,42 \mathrm{t} \mathrm{ha}^{-1}$, uma vez que a produção de colmos $(130,73$ t.ha $\left.^{-1}\right)$ é praticamente duplicada. Os resultados corroboram com Trivelin et al. (1996) que relatam que a quantidade de palhada de canaviais colhidos sem queima varia de 10 a $30 \mathrm{t} \mathrm{ha}^{-1}$.

A alta produção de palhada em sistemas de cultivos irrigados no semiárido pode representar agregação de valor à produção de energia, uma vez que além do etanol produzido na moagem dos colmos da cana-de-açúcar e da utilização do bagaço em caldeiras para produção de energia elétrica; a palhada (folhas + ponteiras) também pode ser utilizada nas caldeiras que alimentam as turbinas nas usinas e aumentam a produção de energia elétrica. Além disso, a utilização da palhada requer que a colheita seja feita sem a queima da cana, o que contribui para a redução da emissão de $\mathrm{CO}_{2}$, diminuindo a produção de fuligem e, consequentemente, melhorando as condições do ar nas áreas circunvizinhas à usina, atendendo ao apelo da sociedade por uma agricultura mais sustentável.

Tabela 05 - Médias de produção de biomassa
fresca da palha (BFP), biomassa
seca da palha (BSP), biomassa
fresca do colmo (BFC) e biomassa
seca do colmo (BSC) em função de
diferentes cultivares e lâminas de
irrigação.

\begin{tabular}{ccccc}
\hline \multirow{2}{*}{$\begin{array}{c}\text { Lâminas } \\
(\%)\end{array}$} & BFP & BSP & BFC & BSC \\
\cline { 2 - 5 } & \multicolumn{5}{c}{$\mathbf{t ~ h a ~}^{-1}$} \\
\hline 40 & 24,58 & 21,27 & 106,24 & 69,33 \\
60 & 33,22 & 29,70 & 135,42 & 96,25 \\
80 & 39,42 & 32,49 & 143,75 & 93,46 \\
100 & 32,49 & 29,07 & 137,50 & 88,94 \\
\hline d.m.s. & 13,15 & 12,98 & 40,61 & 28,27 \\
\hline Médias & 32,42 & 28,13 & 130,73 & 86,99 \\
\hline
\end{tabular}

Onde: d.m.s. = diferença mínima significativa; $\mathrm{BFP}=$ biomassa fresca da palha; $\mathrm{BSP}=$ biomassa seca da palha; $\mathrm{BFC}=$ biomassa fresca do colmo; $\mathrm{BSC}=$ biomassa seca do colmo. 
A média de 130,73 $\mathrm{t} \mathrm{ha}^{-1}$ encontrada para biomassa fresca do colmo corrobora com o trabalho de Gava et al. (2011) que ao estudarem o efeito da tecnologia de irrigação por gotejamento, em cultivares de cana-deaçúcar, concluíram que no segundo ciclo (cana-soca), a média de produtividade de colmos (biomassa fresca de colmos) foi de $126,2 \mathrm{t} \mathrm{ha}^{-1}$.

De acordo com as Figuras 03 e 04, pode-se observar que a lâmina de irrigação baseada em $40 \%$ da ETc proporcionou biomassa fresca total e biomassa seca total inferior às demais lâminas de irrigação. Depreende-se que as cultivares de cana-de-açúcar quando submetidas à lâmina de irrigação de apenas $40 \%$ da ETc, durante os sete meses que antecedem a colheita, em sistema de irrigação por gotejamento subsuperficial e em cana-soca de primeira folha não expressam o máximo de produtividade. Por outro lado, apenas a aplicação da lâmina de irrigação que corresponde a $60 \%$ da ETc é suficiente para atingir produtividade similar àquela encontrada em lâmina de $100 \%$ da ETc.

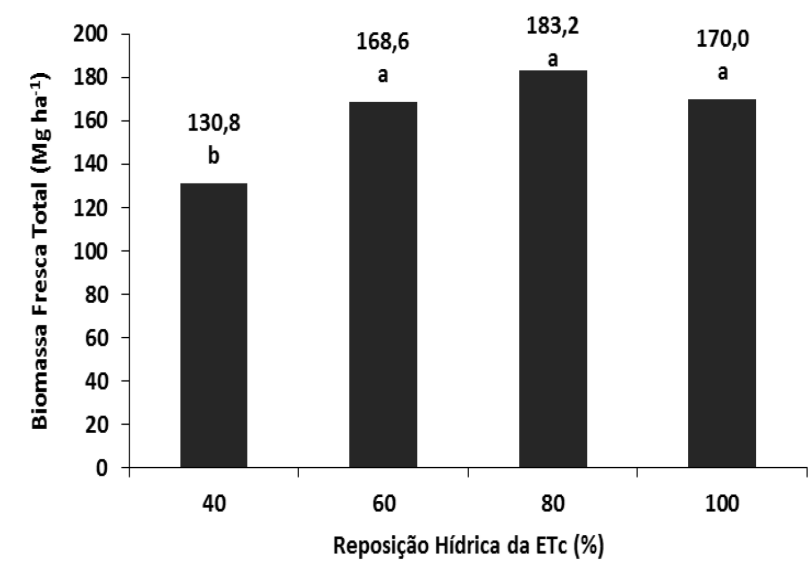

Figura 03 - Produção de biomassa fresca total $\left(t_{h}{ }^{-1}\right)$ de cultivares de cana-deaçúcar em função da reposição hídrica da ETc (\%).

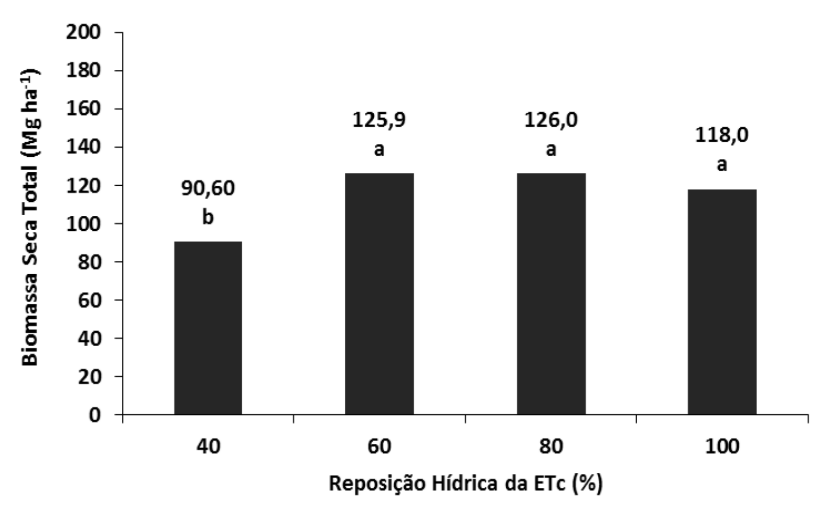

Figura 04 - Produção de biomassa seca total $\left(t h a^{-1)}\right.$ de cultivares de cana-deaçúcar em função da reposição hídrica da ETc (\%).
Ressalta-se que a produção de biomassa alcançada ou mesmo a produtividade de colmos é resultante de irrigação durante todo o período de condução da cultura nas condições climáticas do semiárido. Sendo assim, a produtividade alcançada é superior à média do país e de outras regiões dependentes de chuva.

Dalri e Cruz (2002) utilizando irrigação por gotejamento subsuperficial no cultivo da variedade RB 72-454, cuja frequência era baseada no controle de evaporação do Tanque Classe "A", observaram que mesmo com restrição hídrica a cultura alcançou produtividade de colmos (cana soca) de 143,90; 146,84 e 138,28 $\mathrm{tha}^{-1}$ com frequências de reposição na evaporação de $10 \mathrm{~mm}$, $20 \mathrm{~mm}$ e $30 \mathrm{~mm}$, respectivamente, sendo tais produtividades estatisticamente iguais.

Ressalta-se a importância da produção de fitomassa aérea da cana-de-açúcar no sequestro de carbono. Em estudo de Chohfi (2004), analisando o balanço de emissão e sequestro de $\mathrm{CO} 2$ na geração de eletricidade excedente no setor sucroalcooleiro, foi observado que 145,3 toneladas de $\mathrm{CO} 2 /$ hectare/ciclo são sequestradas no cultivo da cana-de-açúcar e 111,5 toneladas de $\mathrm{CO} 2 /$ hectare/ciclo são emitidas na cogeração de eletricidade excedente, resultando no saldo favorável de sequestro de $\mathrm{CO} 2$ de 33,8 toneladas/hectare/ciclo de vida de eletricidade excedente, quantia que é fornecida às empresas de distribuição de energia.

Levando-se em consideração que além do uso do bagaço, pode-se utilizar a palhada, este saldo positivo poderá ser muito maior. Sendo assim, as usinas poderão contribuir com a redução da emissão de CO2 na atmosfera, produzindo energia limpa e com possibilidades de obtenção de benefícios por meio de créditos de carbono.

\section{Análise da Produção de Fitomassa do Sistema Radicular}

Em relação à distribuição de raízes depreende-se, da Tabela 06, que há maior concentração de raízes nas primeiras camadas do solo, sendo estas favorecidas pelo sistema de irrigação por gotejamento subsuperficial que se situa há $0,20 \mathrm{~m}$ de profundidade. Esta observação corrobora com o trabalho de Faroni (2004) que estudando o sistema radicular de cana-de-açúcar observou que $74 \%$ das raízes, em média, localizaram-se nos $0,20 \mathrm{~m}$ superficiais do solo. Considerando os primeiros $0,40 \mathrm{~m}$ superficiais, essa porcentagem aumenta para $92 \%$, restando $8 \%$ das raízes de 0,40 a $0,80 \mathrm{~m}$ de profundidade. Farias et al. (2008), avaliando os índices de crescimento da parte aérea e do sistema radicular da variedade SP 79-1011 de cana-de-açúcar, em regime irrigado e de sequeiro, concluíram que $75 \%$ das raízes se encontram nos primeiros $0,45 \mathrm{~m}$ de profundidade. 
Tabela 6 - Produção média de biomassa seca do sistema radicular das cultivares de cana-de-açúcar submetidas à lâmina de reposição hídrica de $100 \%$ da ETc em condições semiáridas.

\begin{tabular}{ccccc}
\hline & \multicolumn{2}{c}{ RB 72-454 } & \multicolumn{2}{c}{ RB 92-579 } \\
\cline { 2 - 5 } Profundidade (m) & Trincheira 1 & Trincheira 2 & Trincheira 1 & Trincheira 2 \\
& \multicolumn{5}{c}{ t ha $^{-1}$} \\
\cline { 2 - 5 } & \multicolumn{3}{c}{3,62} & 3,45 \\
$0-0,10$ & 5,76 & 8,37 & 4,13 & 6,06 \\
$0,10-0,20$ & 7,67 & 6,03 & 4,76 & 4,99 \\
$0,40-0,60$ & 7,09 & 9,51 & 0,35 & 0,59 \\
$0,60-1,00$ & 3,24 & 0,91 & 0,06 & 0,03 \\
\hline Total & 0,36 & 0,02 & 12,92 & 15,12 \\
\hline
\end{tabular}

Alvarez (2000), estudando o crescimento de raízes de cana crua e cana queimada (colheita sem despalha a fogo), verificou que há maior acúmulo de raízes em superfície na cana crua do que na queimada, devido a maior umidade em solo coberto com palha, que não estimula o crescimento radicular até camadas mais profundas.

Smith (1998) verificou que com a remoção de 50\% das raízes das plantas de cana-de-açúcar, o uso da água e a taxa de alongamento da planta diminuíram apenas $10 \%$, o que evidencia que a cana-de-açúcar tem mais raízes do que necessita para atingir seu máximo crescimento. Paulino et al. (2011) concluíram que o aumento da quantidade de raízes no perfil do solo não implica em maiores produtividades para cultura de cana-de-açúcar.

Sabe-se que a dinâmica de desenvolvimento do sistema radicular da cana-de-açúcar está associada à disponibilidade de água no solo (VASCONCELOS, 2002; SMITH et al., 2005). Isto indica que, em estudos que avaliam o sistema radicular de cana-de-açúcar, é importante avaliar também a umidade do solo, ou preferivelmente o armazenamento de água no solo (até a profundidade em que se pretende realizar o estudo das raízes), para auxiliar no entendimento da dinâmica de crescimento do sistema radicular da cultura.

É necessário mais estudos sobre a produção de biomassa de raízes de cana-de-açúcar a fim de maior respaldo às demandas oriundas de quantificação de sequestro de carbono para fins de obtenção de créditos de carbono.

\section{CONCLUSÃO}

As cultivares de cana-de-açúcar RB 72-454 e RB 92-579, em cana soca, quando submetidas ao estresse hídrico apresentam número de perfilhos, diâmetro do colmo e altura semelhantes. A altura dos colmos é afetada pela lâmina de reposição de apenas $40 \%$ da ETc;

$\checkmark$ A produção média de palha $\left(32,42 \mathrm{tha}^{-1}\right) \mathrm{e}$ colmos $\left(130,73 \mathrm{tha}^{-1}\right)$ das cultivares RB 72-454 e RB 92-579 em condições irrigadas por gotejamento subsuperficial no semiárido é maior do que em outras regiões, mesmo em condições de déficit hídrico;

$\checkmark$ A produção de biomassa fresca e seca total das canas que receberam 60,80 e $100 \%$ de ETc foram iguais e superiores àquelas que receberam $40 \%$;

$\checkmark \quad$ A alta produção de palhada no cultivo da canade-açúcar irrigada no semiárido apresenta potencial para cogeração de energia;

$\checkmark$ A elevada produção de biomassa do sistema radicular somada à produção de biomassa da parte aérea apresenta potencial para agregação de valor por meio da obtenção de créditos de carbono de acordo com o MDL.

\section{AGRADECIMENTO}

Ao Banco do Nordeste do Brasil (BNB) pelo apoio financeiro à pesquisa.

\section{REFERÊNCIAS}

ABRAMO FILHO, J. et al. Resíduo de colheita mecanizada de cana crua. Álcool \& Açúcar, São Paulo, n .67, p. 23-25, 1993.

ALMEIDA, A. C. S. et al. Desenvolvimento vegetativo e produção de variedades de cana-deaçúcar em relação à disponibilidade hídrica e unidades térmicas. Ciência e Agrotecnologia, Lavras, v. 32, n. 5, p.1441-1448, 2008.

ALVAREZ, I. A.; CASTRO, P. R. C.; NOGUEIRA, M. C. S. Crescimento de raízes de cana crua e queimada em dois ciclos. Scientia Agrícola, Piracicaba, v. 57, n. 4, p. 653-659, 2000.

ALVAREZ, I. A.; CASTRO, P. R. C. Crescimento da parte área de cana crua e cana queimada.

Scientia Agricola, Piracicaba, v. 56, n. 4, p. 10691079, 1999. 
AMORIM, F. A. M.; AMORIM, J. N.; BRITTO,

W. S. F. Custos de irrigação na cana-de-açúcar: um estudo realizado com os diversos sistemas de irrigação em Juazeiro-BA. 2007. In: CONGRESSO BRASILEIRO DE CUSTOS, 14., João Pessoa.

Anais... Disponível em: < http://www.abcustos.org.br/texto/viewpublic?ID_T $\mathrm{EXTO}=2416>$. Acesso em: 03 mar. 2013.

BACHCHHAV, S. M. Fertigation technology for increasing sugarcane production. Indian Journal of Fertilisers, New Delhi, v. 1, n. 4, p. 85-92, 2005.

BARBOSA, A. B. Avaliação fitotécnica de cinco variedades de cana-de-açúcar para o município de Salinas - MG. 2005. 70 p. Dissertação

(Mestrado em Agronomia)- Universidade Estadual do Sudoeste da Bahia, Vitória da Conquista, 2005.

BARBOSA, E. A. A. et al. Cana-de-açúcar fertirrigada com vinhaça e adubos minerais via irrigação por gotejamento subsuperficial: ciclo da cana-planta. Revista Brasileira de Engenharia Agrícola e Ambiental. Campina Grande, v. 16, n. 9, p. 952-958, 2012.

BEEHARRY, R. P. Strategies for augmenting sugarcane biomass availability for power production in Mauritius. Biomass \& Bioenergy, Aberdeen, v. 20, n. 6, p. 421-29, 2001.

BERNARDO, S. Manejo da irrigação na cana-deaçúcar. Alcoolbrás, São Paulo, n. 106, p. 72-80, 2006.

CAMPOS, L. H. F. et al. Sistemas de manejo da palhada influenciam acúmulo de biomassa e produtividade da cana-de-açúcar (var. RB855453). Acta Scientiarum Agronomy, Maringá, v. 32, n. 2, p. 345-350, 2010.

CANELLAS, L. P. et al. Estoque e qualidade da matéria orgânica de um solo cultivado com canade-açúcar por longo tempo. Revista Brasileira de Ciência do Solo,Viçosa, MG, v. 31, n. 2, p. 331340, 2007.

CASAGRANDE, A. A. Tópicos de morfologia e fisiologia da cana-de-açúcar. Jaboticabal: FUNEP, 1991. $157 \mathrm{p}$.

CHANDEL, A. K. et al. Sugarcane bagasse and leaves: foreseeable biomass of biofuel and bioproducts. Journal of Chemical Technology and
Biotechnology, Malden, v. 87, n. 1, p. 11-20, 2011.

CHOHFI, F. M. Balanço, análise de emissão e seqüestro de $\mathrm{CO} 2$ na geração de eletricidade excedente no setor sucro-alcooleiro. 2004. 81 p. Dissertação (Mestrado em Engenharia da Energia)Universidade Federal de Itajubá, Itajubá, 2004.

\section{COMPANHIA NACIONAL DE}

ABASTECIMENTO. A geração termoelétrica com a queima do bagaço de cana-de-açúcar no Brasil: análise do desempenho da safra 2009-2010. 2011. Disponível em:

$<$ http://www.conab.gov.br/OlalaCMS/uploads/arqui vos

/11_05_05_15_45_40_geracao_termo_baixa_res..p df $>$. Acesso em: $1 \overline{8}$ abr. 2013.

COSTA, C. T. S. Crescimento, pigmentos fotossintéticos e produtividade de cana-deaçúcar (Saccharum sp.), no quarto ciclo de cultivo. 2009. 5 1p. Dissertação (Mestrado em Agronomia/ Produção Vegetal)- Centro de Ciências Agrárias, Universidade Federal de Alagoas, Rio Largo, 2009.

CZYCZA, R. V. Quantidade e qualidade da matéria orgânica do solo em sistemas de colheita com e sem queima da cana-de-açúcar. 2009. 92 p. Dissertação (Mestrado em Solos e Nutrição de Plantas)-Escola Superior de Agricultura "Luiz de Queiroz”, Universidade de São Paulo, Piracicaba, 2009.

DALRI, A. B.; CRUZ, R. L. Efeito da frequência de irrigação subsuperficial por gotejamento no desenvolvimento da cana-de-açúcar (Saccharum spp.). Irriga, Botucatu, v. 7, n. 1, p. 29-34, 2002.

DIAS, C. M. O. et al. Indicadores fitotécnicos de produção e agroindustriais em cana-de-açúcar cultivada sob dois regimes hídricos. Revista Caatinga, Mossoró, v. 25, n. 3, p. 58-65, 2012. ERNEST \& YOUNG TERCO. Brasil sustentável: perspectivas dos mercados de petróleo, etanol e gás. São Paulo, 2011. 69 p.

FARIAS, C. H. A. et al. Índices de crescimento da cana-de-açúcar irrigada e de sequeiro no Estado da Paraíba. Revista Brasileira de Engenharia Agrícola e Ambiental, Campina Grande, v. 12, n. 4, p. 356-362, 2008. 
FARONI, C. E. Sistema radicular de cana-deaçúcar e identificação de raízes metabolicamente ativas. 2004. 68 p. Dissertação (Mestrado em Solos e Nutrição de Plantas)-Escola Superior de Agricultura "Luiz de Queiroz", Universidade de São Paulo, Piracicaba, 2004.

FLORENTINO, H. O.; MORENO, E. V.; SARTORI, M. M. Multiobjective optimization of economic balances of sugarcane harvest biomass. Scientia Agricola, Piracicaba, v. 65, n. 5, p. 561564, 2008.

FREITAS, C. A. S. et al. Crescimento vegetativo da cana-de-açúcar (Saccharum officinarum L.) irrigada com água de esgoto doméstico tratado. Conexões Ciência e Tecnologia, Fortaleza, v. 6, n. 1, p. 27 43, 2012.

GAVA, G. J. C. et al. Produtividade de três cultivares de cana-de-açúcar sob manejos de sequeiro e irrigado por gotejamento. Revista Brasileira de Engenharia Agrícola e Ambiental, Campina Grande, v. 15, n. 3, p. 250-255, 2011.

GODOY, S. G. M.; PAMPLONA, J. B. O protocolo de Kyoto e os países em desenvolvimento. Pesquisa \& Debate, São Paulo, v. 18, n. 2, p.329-353, 2007.

GOLDEMBERG, J. Pesquisa e desenvolvimento na área de energia. São Paulo em Perspectiva, São Paulo, v. 14, n. 3, p. 91-97, 2000.

HILGEMBERG, E. M.; GUILHOTO, J. J. M. Uso de combustíveis e emissões de $\mathrm{CO}_{2}$ no Brasil: um modelo inter-regional de insumo-produto. Nova Economia, Belo Horizonte, v. 16, n. 1, p. 49-99, 2006.

LAMONICA, H. M. Potencial de geração de excedentes de energia elétrica com o biogás produzido a partir da biodigestão da vinhaça na indústria sucro-alcooleira brasileira. In: ENCONTRO DE ENERGIA NO MEIO RURAL, 6., 2006, Campinas. Proceedings online...

Disponível em:

$<$ http://www.proceedings.scielo.br/scielo.php?scrip $\mathrm{t}=$ sci_arttext\&pid=MSC0000000022006000200027 \&lng=en\&nrm=abn>. Acesso em: 25 nov. 2012.

OLIVEIRA, F. C. et al. Crescimento da cultura da cana-de-açúcar irrigada. In: WORKSHOP INTERNACIONAL DE INOVAÇÕES
TECNOLÓGICAS NA IRRIGAÇÃO, 4., 2012, Fortaleza. Anais... Disponível em: $<$ http://www.inovagri.org.br/meeting2012/wpcontent/uploads/2012/06/Protocolo367.pdf>. Acesso em: 03 mar. 2013.

OLIVEIRA, R. A. et al. Crescimento e desenvolvimento de três cultivares de cana-deaçúcar, em cana-planta, no estado do Paraná. Scientia Agraria, Curitiba, v. 5, n. 1/2, p. 87-94, 2004.

ORLANDO FILHO, J. et al. Adubação de soqueira de cana-de-açúcar sob dois tipos de despalha: cana crua x cana queimada. STAB- Açúcar, Álcool e Subprodutos, Piracicaba, v. 12, n. 4, p. 7-11, 1994.

OTTO, R. et al. Root system distribution of sugar cane as related to nitrogen fertilization, evaluated by two methods: monolith and probes. Revista Brasileira de Ciência do Solo, Viçosa, v. 33, n. 3, p. $601-611,2009$.

PAES, L. A. D.; OLIVEIRA, M. A. Potential trash biomass of the sugar cane plant. In: SULEIMAN, J. H.; LEAL, M. R. L. V.; MACEDO I. A. (Ed.).

Biomass power generation: sugar cane bagasse and trash. Piracicaba: Centro de Tecnologia Canavieira, 2005. p. 19-23.

PAOLIELLO, J. M. M. Aspectos ambientais e potencial energético no aproveitamento de resíduos da indústria sucroalcooleira. 2006. 180 p. Dissertação (Mestrado em Engenharia Industrial)- Faculdade de Engenharia, Universidade Estadual Paulista, Bauru, 2006.

PAULINO, J. et al. Estudo exploratório do uso da vinhaça ao longo do tempo: II. Características da cana-de-açúcar. Revista Brasileira de Engenharia Agrícola e Ambiental, Campina Grande, v. 15, n. 3, p. 244-249, 2011 .

\section{REDE INTERUNIVERSITÁRIA PARA O DESENVOLVIMENTO DO SETOR SUCROENERGÉTICO - RIDESA. 2010. Tecnologia. Disponível em: $<$ http://www.ridesa.agro.ufg.br/pages/38086>. Acesso em: 18 abr. 2013.}

REDIN, M. et al. Impactos da queima sobre atributos químicos, físicos e biológicos do solo. Ciência Florestal, Santa Maria, v. 21, n. 2, p. 381392, 2011. 
RIBEIRO, H. Queimadas de cana-de-açúcar no Brasil: efeitos à saúde respiratória. Revista de Saúde Pública, São Paulo, v.42, n.2, p.370-376, 2008.

RIPOLI, T. C. C.; MOLINA JÚNIOR, W. F.; RIPOLI, M. L. C. Energy potential of sugar cane biomass in Brazil. Scientia Agricola, Piracicaba, v. 57, n. 4, p. 677-681, 2000.

RIPOLI, T. C. C.; NOVA; N. A. V.; RIPOLI, M. L. $\mathrm{C}$. Sugar cane crop residues and bagasse for energy co-generation in Brazil. Biomassa \& Energia, Viçosa, v. 2, n. 3, p. 205-211, 2005.

RONQUIM, C. C. Queimada na colheita de canade-açúcar: impactos ambientais, sociais e econômicos. Campinas: Embrapa Monitoramento por Satélite, 45p. 2010. (Documentos, 77).

\section{SANTOS, V. R. Fontes de fósforo e} parcelamento da adubação fosfatada na canade-açúcar (Saccharum spp.). 2006. 66 p. Dissertação (Mestrado em Agronomia/Produção Vegetal)- Universidade Federal de Alagoas, Rio Largo, 2006.

SILVA, M. A. et al. Agronomic performance of sugarcane families in response to water stress.

Bragantia, Campinas, v. 67, n. 3, p. 656-661, 2008.

SILVA, N. F. N. et al. Análise das variáveis de produtividade da cana-de-açúcar irrigada por gotejo subsuperficial. In: WORKSHOP

INTERNACIONAL DE INOVAÇÕES

TECNOLÓGICAS NA IRRIGAÇÃO, 4., 2012,

Fortaleza. Anais... Disponível em:

$<$ http://www.inovagri.org.br/meeting2012/wp-

content/uploads/2012/06/Protocolo378.pdf $>$.

Acesso em: 03 mar. 2013.

SMITH, D. M.; INMAN-BAMBER, N. G.; THORBURN, P. J. Growth and function of the sugarcane root system. Field Crops Research, Amsterdam, v. 92, p. 169-183, 2005.

SMITH, J. P. Studies on the relation between root growth and shoot growth of sugarcane. 1998. 132 p. Thesis (PhD)-James Cook University of North Queensland, Townsville, 1998.

SOUZA, S. A. V. Disponibilidade e uso de água no Brasil: irrigação. In: MACEDO, I. C. (Org.). A energia da cana-de-açúcar: doze estudos sobre a agroindústria da cana-de-açúcar no Brasil e a sua sustentabilidade. São Paulo: Única, 2005. 102$106 p$.

TRIVELIN, P. C. O.; RODRIGUES, J. C. S.; VICTORIA, R. L. Utilização por soqueira de canade-açúcar de início de safra do nitrogênio da aquamônia-15N e uréia-15N aplicado ao solo em complemento a vinhaça. Pesquisa Agropecuária Brasileira, Brasília, DF, v. 31, n. 2, p. 89-99, 1996.

VARELA, A. C. G. Análise do comportamento morfofisiológico da cana-de-açúcar irrigada (variedades SP 79-1011 e SP 71-6949), nos Tabuleiros Costeiros Paraibanos. 2002. 82 p. Dissertação (Mestrado em Engenharia Agrícola)Universidade Federal de Campina Grande, Campina Grande, 2002.

VASCONCELOS, A. C. M. Desenvolvimento do sistema radicular e da parte aérea de socas de cana-de-açúcar sob dois sistemas de colheita: crua mecanizada e queimada manual. 2002. 140 p. Tese (Doutorado em Agronomia) - Faculdade de Ciências Agrárias e Veterinárias, Jaboticabal, 2002.

VICHI, F. M.; MANSOR, M. T. C. Energia, meio ambiente e economia: o Brasil no contexto mundial. Química Nova, São Paulo, v. 32, n. 3, p. 757-767, 2009.

VIEIRA, V. J. S. Determinar a evapotranspiração e o coeficiente de cultivo da cana-de-açúcar irrigada por gotejamento sub-superficial. 2012. Disponível em: <http://www.codevasf.gov.br/.../apresentacao8-agrovale-profo-vinicius-part...>. Acesso em: 18 abr. 2012. 